\title{
The Optimization Of Boiler Operation Based On Intelligent Algorithm
}

\author{
Xinli Zhou
}

\author{
School of North China Electric Power University, Baoding 071000, China; \\ 1297682657@qq.com
}

Keywords: controllable operating parameters; genetic algorithm; nonlinear programming

\begin{abstract}
Boiler efficiency is influenced by many factors. In order to find and realize optimum efficiency of boiler, the concept of controllable operating parameter is introduce to select the parameters and optimize them. Finally, 3 parameters are determined to participate in optimization, namely, excess air coefficient $\alpha$, exhaust gas temperature $\vartheta_{\text {py }}$ and main steam flow $D$. Then this paper conclude the relationship between these parameters and boiler efficiency respectively. By using the function optimization algorithm based on genetic algorithm and nonlinear programming, the optimum scheme of boilers and calculate optimal solution of $\eta_{\text {glzy }}$ is achieved, that is $\eta_{\text {glzy }}=93.110 \%$.
\end{abstract}

\section{Introduction}

Boiler is one of the key equipments in thermal power plant, it' s efficiency effect the economy of power plants directly. In modern power station, the main performance index reflecting boiler operation conditions is boiler efficiency. The efficiency of power plant boiler are calculated by using a counter balance, namely:

$$
\eta_{g l}=q_{1}=\frac{Q_{1}}{Q_{r}} \times 100=100-\left(q_{2}+q_{3}+q_{4}+q_{5}+q_{6}\right), \%
$$

Where: $q_{1}$ : the effective utilization of heat

$q_{2}$ :heat loss due to exhaust gas

$q_{3}$ : heat losing of chemistry $q_{4}$ : mechanical incomplete combustion heat loss

$q_{5}$ : heat losing of dispelling heat of boiler $\quad q_{6}$ : the physical heat loss of ash and slag

There are some researches indicate the relationship between $q_{2}, q_{3}, q_{4}$ and $\alpha$ [1], finding optimum excess air coefficient $\alpha$ to make minimum heat loss, so boiler optimum efficiency problem is solved by optimum excess air coefficient model. They get the relationship between excess air coefficient $\alpha$ and $q_{2}, q_{3}, q_{4}$ :

$$
q_{2}+q_{3}+q_{4}=4.283 \alpha+\frac{53.19}{\alpha+1.009}+\frac{0.0002106}{\alpha+0.14}-\frac{53.19}{\alpha-3.775}-41.16
$$

Then they get the conclusion that when the optimum excess air coefficient $\alpha_{p}=1.152596$,the boiler efficiency is the best. However, this paper aim to find the best boiler efficiency and optimize it in other aspects, not only $q_{2}, q_{3}, q_{4}$, but also $q_{5}, q_{6}$, exhaust gas temperature ${ }^{\vartheta_{\mathrm{py}}}$, and main steam flow $D$, etc.

\section{Determination of optimal parameters - controllable operating parameters[2]}

Parameters which influence economic operation of boilers are composed of controllable operating parameters and uncontrollable operating parameters. Nowdays, the power plants usually adopt checking method of small operating indices, namely to check carbon content in fly ash, exhaust gas temperature, boiler efficiency,power consumption of the auxiliary equipment and so on. Although all these parameters determine the economic operation of equipments, they are not the most immediate 
parameters. So we introduce concept of controllable operating parameters, which effect the economy significantly and operating personnel can adjust them directly.

Uncontrollable operating parameters usually include: ambient temperature, load of boiler, boiler load, kind of coal and coal fineness, etc. Controllable operating parameters can be controlled and adjusted at any time. It is of great pertinence and practical significance to adopt these parameters to operate optimally. We make comprehensive consideration of the parameters and finally 3 parameters are determined to participate in optimization, namely, air coefficient $\alpha$ 、 Exhaust Gas Temperature $^{\vartheta_{\mathrm{py}}}$ 、 main steam flow $D$.

\section{Optimum excess air coefficient}

In foundation of heat balance principle[3],boiler efficiency can be achieved by calculating each heat loss . So we conduct further discussion on $q_{5}$ and ${ }^{q_{6}}$, finding the relationship between $\alpha$ and $q_{5}, q_{6}$ and then get the relationship of $\alpha$ and $\eta_{g l}$.

- calculation of heat loss $q_{5}$

When a boiler is running, furnace wall,pipeline and some other parts are always higher than the ambient air temperature, the percentage of heat losing of dispelling heat of boiler accounts for heat input is $q_{5}$, which is calculated by the following formula:

$$
q_{5}=5.82(D)^{-0.38}
$$

Where $D$ denotes main steam flow, the empirical data of $D$ is $1074 \mathrm{t} / \mathrm{h}$.By running the program,we get $q_{5}=0.4102$.

- Calculation of the physical heat loss of ash and slag $q_{6}$

Generally speaking,we only take ${ }^{q_{6}}$ into consideration under the following condition[4]:

(1)Slag tap boiler with large amount of ash and high temperature

(2)Stoker furnace with large amount of ash

(3)Solid state slag-tap coal dust boilers which burn high ash coal

The computational formula of $Q_{6}$ is:

$$
\mathrm{Q}_{6}=\frac{A^{\mathrm{y}}}{100}\left[\frac{a_{f h}\left(\vartheta_{p y}-t_{0}\right) c_{f h}}{100-C_{f h}}+\frac{a_{l z}\left(t_{l z}-t_{0}\right) c_{l z}}{100-C_{l z}}+\frac{a_{c j h}\left(t_{c j h}-t_{0}\right) c_{c j h}}{100-C_{c j h}}\right], k J / k g \text { (4) }
$$

Where $C_{f h} 、 C_{l z} 、 C_{c j h}$ represent thespecific heat of fly ash, slag and fallout.We can get their specific values by looking up <specific heat capacity scale of solid fuel ash $>, a_{c j h}$ is so small that we neglect it. Then we get:

$$
Q_{6}=\frac{A^{\mathrm{y}}}{100}\left[\frac{a_{f h}\left(\vartheta_{p y}-t_{0}\right) c_{f h}}{100-C_{f h}}+\frac{a_{l z}\left(t_{l z}-t_{0}\right) c_{l z}}{100-C_{l z}}\right](5)
$$

Because $q_{6}=\frac{Q_{6}}{Q_{r}}$ and $C_{\text {fh }}$ is the function of $\alpha$,we get the following figure:

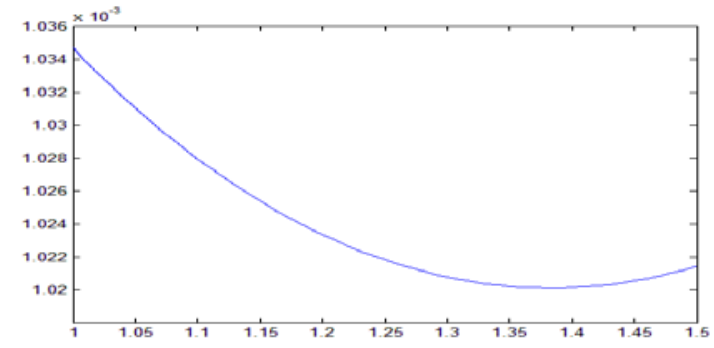

Fig. 1 The relationship between physical heat loss of ash and slag and excess air coefficient 
According to the above figure we can see that ${ }^{q_{6}}$ decrease first and then increase with the increase of $\alpha$ and the magnitude of $q_{6}$ is $10^{-3}$, which is relatively small. We introduce ash converted by coal-fired $A_{z s}$ as the constraint. When $\left.A_{z s<10 \%} A_{z s}=\frac{4187 A_{y}}{Q_{a r, n e t}}\right)$, we will neglect the heat losing of dry-bottom boiler fired pulverized coal . We calculate that $A_{z s}=2.56 \%<<10 \%$, so we neglect it.

- The relationship of boiler efficiency and excess air coefficient

According to the formula(2),(3), we get the formula of boiler efficiency dependence of excess air coefficient by using back balance method.

$$
\begin{aligned}
& \eta_{g l}=1-(q 2+q 3+q 4+q 5+q 6) \\
& =-\frac{45.99\left(15.46 \alpha^{2}-42.76 \alpha+33.6\right)}{-16.71 \alpha^{2}+46.23 \alpha+63.68}+\left(\frac{0.002916}{\alpha+0.14}-1.368\right) 0.4866(6.321 \alpha+0.7388)-0.07486 \alpha+98.69
\end{aligned}
$$

Simplifying the above formula by MATLAB :

Then we get the figure below:

$$
\eta_{g l}=140.7-\frac{53.19}{\alpha-3.775}-\frac{53.19}{\alpha+1.009}-\frac{0.0002106}{\alpha+0.14}-4.283 \alpha(7)
$$

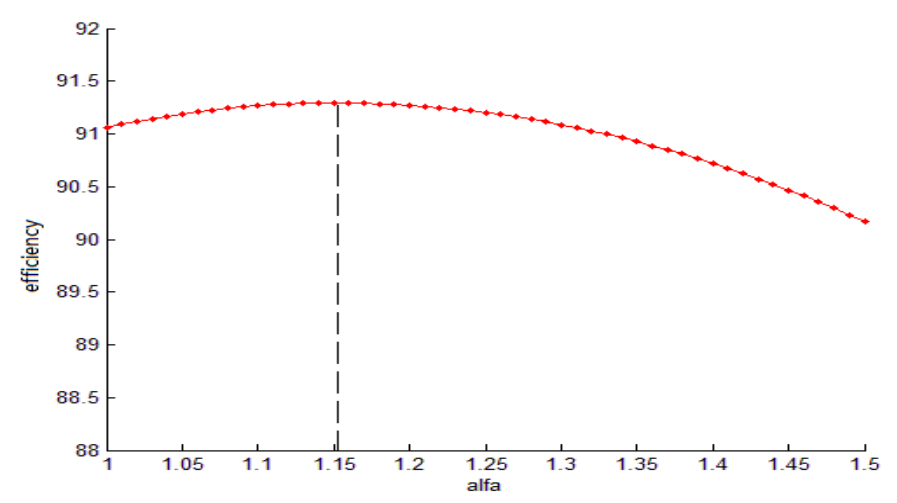

Fig 2. The relationship of boiler efficiency and excess air coefficient

\section{- The influence on the boiler efficiency from exhaust gas temperature $\theta_{p y}$}

As the main heal losses, heat loss due to exhaust gas decide the improvement of boiler efficiency directly. Heat loss due to exhaust gas mainly depends on exhaust gas temperature and exhaust gas volume. When the fuel and air supply conditions are stable, changes of exhaust gas volume can be neglect and so it is important to find the influence trend of exhaust gas temperature $\theta_{p y}$ on boiler efficiency.

Exhaust gas is bound to consume part of the fuel when it change from cold air into the exhaust, thus forming heat loss due to exhaust gas[5]. It is obviously that heat loss due to exhaust gas increase with the increase of exhaust gas temperature ${ }^{\theta_{p y}}$,so we find the relationship between $\theta_{p y}$ and heat loss due to exhaust gas and then find the influence on the boiler efficiency from $\theta_{p y}$.

The relationship between exhaust gas temperature $\vartheta_{\mathrm{py}}$ and heat loss due to exhaust gas $q_{2}$ is calculated as the following formulas:

Where:

$$
q_{2}=\frac{Q_{2}}{Q_{r}} \times 100 \%
$$

$$
Q_{2}=\mathrm{Q}_{2}^{\mathrm{gy}}+Q_{2}^{H_{2} \mathrm{O}}, \mathrm{kJ} / \mathrm{kg}
$$




$$
\begin{aligned}
Q_{2}^{\mathrm{gy}} & =V_{\mathrm{gy}} \mathrm{c}_{\mathrm{p}, \mathrm{gy}}\left(\vartheta_{\mathrm{py}}-\mathrm{t}_{0}\right), \mathrm{kJ} / \mathrm{kg}(10) \\
Q_{2}^{H_{2} \mathrm{O}} & =V_{\mathrm{H}_{2} \mathrm{O}} \mathrm{c}_{\mathrm{p}_{\mathrm{H}_{2} \mathrm{O}}}\left(\vartheta_{\mathrm{py}}-\mathrm{t}_{0}\right), \mathrm{kJ} / \mathrm{kg}(11)
\end{aligned}
$$

$\mathrm{Q}_{2}^{\mathrm{gy}}$ : heat carried off by dry flue gas $Q_{2}^{\mathrm{H}_{2} \mathrm{O}}$ : sensible heat of steam contained by flue gas $\mathrm{V}_{\mathrm{gy}}$ : volume of dry flue gas $\quad \mathrm{C}_{\mathrm{p}}$, gy : average specific heat capacity at constant pressure of dry flue gas from ${ }^{\mathrm{t}_{0}}$ to $\vartheta_{\mathrm{py}} \quad \mathrm{c}_{\mathrm{p}, \mathrm{H}_{20} \mathrm{O}}$ : average specific heat capacity at constant pressure of steam from $^{\mathrm{t}_{0}}$ to $\vartheta_{\mathrm{py}}$

Then we get the relationship of $q_{2}$ and $\vartheta_{\text {py }}$ (here we take $\alpha=\alpha_{p}=1.1143$ )

$$
q_{2}=\frac{\left[0.1238\left(\vartheta_{\mathrm{py}}-100\right) / 100+11.0153\right]\left(\vartheta_{\mathrm{py}}-20\right)}{24042}=\left(\vartheta_{\mathrm{py}}-20\right)\left(0.51 \times 10^{-7} \vartheta_{\mathrm{py}}+0.00045\right)
$$

According to the above formula, we can see that itsfigure is a parabola.We select 110-150 degree centigrade as the reference range of exhaust gas temperature and within the scope of this it approximate to a straight line:

$$
K=\left(452+0.1 \vartheta_{\mathrm{py}}\right) 10^{-6}
$$

The function image is shown below:

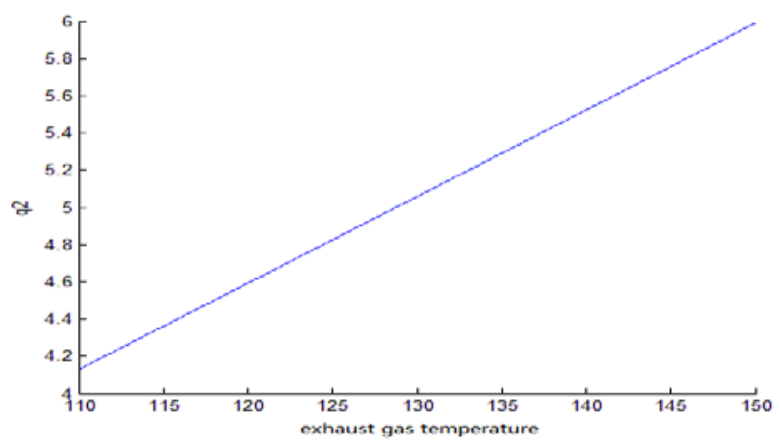

Fig. 3.The relationship of exhaust gas temperature and heat loss due to exhaust gas $q_{2}$

As indicated in the above figure, heat loss due to exhaust gas linearly increases with the increase of exhaust gas temperature. According to the counter balance theory, the increase of $q_{2}$ will lead to the decrease of $\eta_{g l}$ and boiler efficiency will linearly decreases with the increase of exhaust gas temperature.

Generally speaking,if exhaust gas temperature increase by $10-15^{\circ} \mathrm{C}$, the boiler will decrease $1 \%[6]$,which confirms the results of our model excessively,sulfuric acid in the flue gas will condense so that the plants expend additional costs. So in condition of economics, we should choose the exhaust gas temperature reasonably in practice.

\section{A function optimization algorithm based on genetic algorithm and nonlinear programming[7]}

- Function optimization algorithm

For the function optimization problems,genetic algorithm has stronger global search ability and weaker local search ability, we can only get the suboptimal solution of the problem normally.However, nonlinear programming has stronger local search ability while its global search ability is weaker.

We combine the two methods, using genetic algorithm to implement global search and nonlinear programming to implement local search and getting the global optimal solution. By testing function we find that the genetic algorithm not only can solve the problem of local optimum solution but also have high searching efficiency after combined with nonlinear programming and we get a 
satisfactory result.

Flow chart of genetic algorithm is as follows:

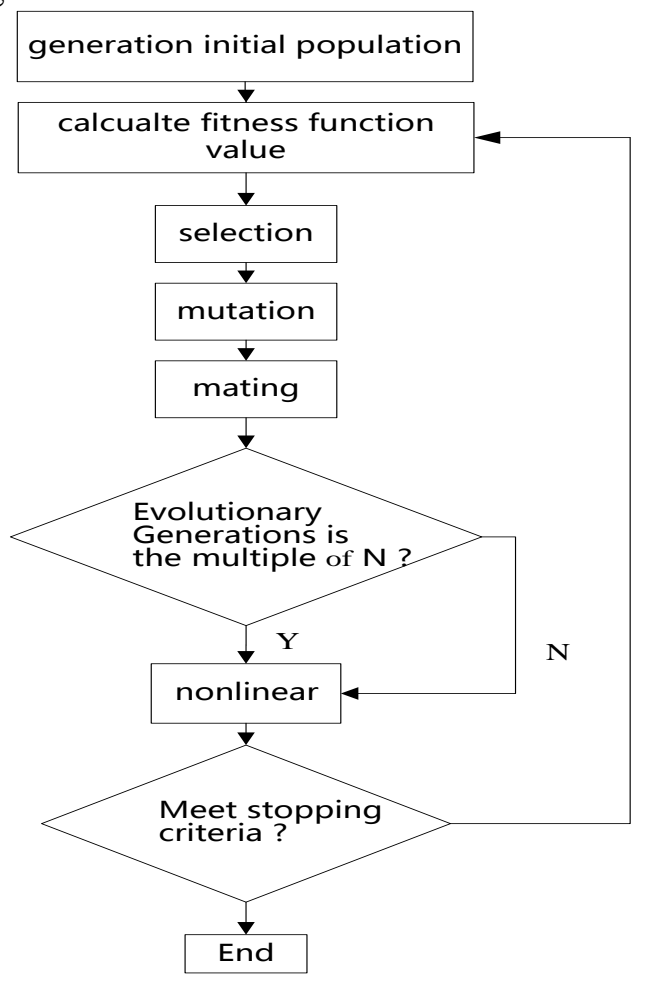

Figure. 4 .flow chart of genetic algorithm

We construct a function optimization algorithm based on genetic algorithm and nonlinear programming to determine optimization scheme and the best boiler efficiency.

We adopt linear programming function, which is in MATLAB optimization toolbox, to optimize:

$$
-\eta=f \min \operatorname{con}\left(\alpha, \theta_{p y}, \mathrm{D}\right)
$$

The constraints are : $1.1 \leq \alpha \leq 1.7 \quad 110 \leq \theta_{p y} \leq 170 \quad 900 \leq D \leq 1704$

- Optimization scheme

Based on genetic algorithm, we find the optimal solutions by using MATLAB. Parameters of genetic algorithm are: population scale is 300 , evolution generations are 2000, crossover probability is 0.6 , mutation probability is 0.1 .

We get the following optimal solutions:

$$
\alpha_{z y}=1.105 ; D_{z y}=1066.329 ; \vartheta_{z y}=110.042 ; \eta_{g l z y}=93.110 \% ;
$$

The table below is the optimization process:

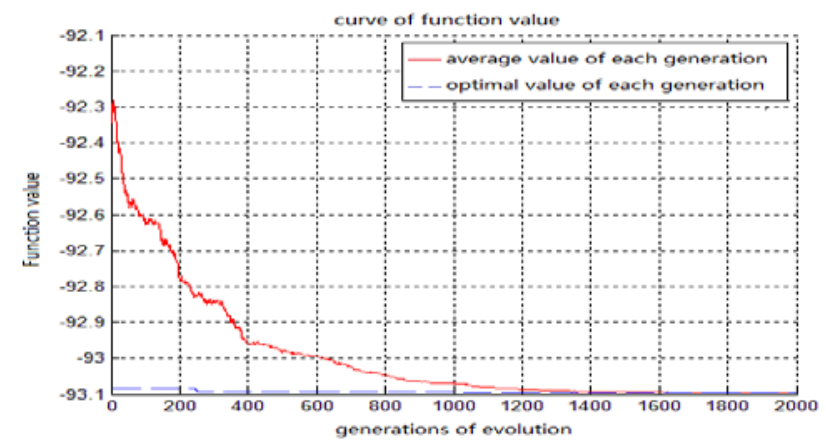

Figure. 5 .optimization process of nonlinear genetic algorithm

According to the above model,we get the optimum scheme of boilers: When $\alpha_{z y}=1.105$, $D_{z y}=1066.329, \vartheta_{z y}=110.042$, Optimal solution of $\eta_{\text {glzy }}$ is : $\eta_{g l z y}=93.110 \%$ 


\section{Summary}

Each parameter is close to the boundary value, which may not be achieved in practice.But we should try to close to the parameters and make the boiler in full-load operation on the premise of ensuring economic and security.

\section{References}

[1]Sun, C. (2014, July). The Optimal Operation Problem of Boilers. In Advanced Materials Research (Vol. 953, pp. 1454-1458).

[2]Yao Yao. (2008). Optimizing Method of Boiler Operation and Its Application . North China electric power technology , (1), 27-31.

[3]Guoguang Zhang,CuiCui Jiang,Ying Jiang, \& Ming Sheng. (2008). the influence on boiler heat balance efficiency from solid incomplete combustion heat loss. technology of coal quality, (5), 50-53.

[4]Zhendong Chen, Bin Sun. Thermal Efficiency Analysis of the Industry Boiler[J]. Taiyuan Science and Technology, 2007, 5: 034.

[5]Yunjia Fu, Chaoyin Ding. The influence on the boiler efficiency from heat loss due to exhaust ga s[J]. Technoingy In West Of China, 2011, 10(004): 16-17.

[6]Jinzhi Wang,Ming Xiao,Chunmin Jiang. The influence on the boiler efficiency from exhaust gas temperature [J]. Shandong Power Technology, 2008, 2: 35-37.

[7]Feng Shi,Hui Wang,Lei Yu, ect. MATLAB Intelligent Algorithm-30 Case Studies[J].Beijing:Be ijing University of Aeronautics and Astronautics Press, 2011. 